\title{
REPRESENTAÇÃO GRÁFICA DE SÍNTESE (RGS) DE DIRETRIZES PARA CRIAÇÃO DE CONTEÚDO DE OBJETOS DE APRENDIZAGEM ACESSÍVEIS
}

\author{
SYNTHESIS GRAPHICAL REPRESENTATION (SGR) OF \\ GUIDELINES FOR CREATION OF ACCESSIBLE LEARNING \\ OBJECT
}

\author{
MUNHOZ, Daniella Rosito Michelena (1); \\ KUNTZ, Viviane (2); \\ ULBRICHT, Vania Ribas (3).
}

(1) UFPR, Mestre

e-mail: daniella.tecnokena@gmail.com

(2) USFC, Mestre

e-mail:vkuntz@gmail.com

(3) USFC, Doutora

e-mail:vrulbricht@gmail.com

\begin{abstract}
RESUMO
O presente artigo apresenta os resultados do trabalho colaborativo desenvolvido pelo grupo de alunos da disciplina de Acessibilidade no Programa de Pós-graduação em Design da UFPR. Este trabalho consiste num exercício de aplicação do conceito da representação gráfica de síntese (RGS) nas 'diretrizes para criação de objetos de aprendizagem acessíveis` da tese de Macedo (2010). O desenvolvimento, a testagem, a análise e a reformulação da RGS foi realizada com o propósito de facilitar o acesso e o uso das diretrizes por usuários desenvolvedores de objetos de aprendizagem OAs que visam atender os propósitos da acessibilidade.
\end{abstract}

Palavras-chave: Acessibilidade, Objetos de Aprendizagem, Representação Gráfica de Síntese.

\begin{abstract}
This article presents the results of the collaborative work of the group of students of the discipline of accessibility at the Graduate Program in Design at UFPR. This work is an exercise in applying the concept of synthesis graphical representations (SGR) in 'guidelines for creation of accessible learning object' Macedo thesis (2010). The development, testing, analysis and reformulation of RGS was performed in order to facilitate access and use of guidelines for developers users of LOs learning objects designed to meet the purposes of accessibility.
\end{abstract}

Key Words: Accessibility, Learning Objects, Synthesis Graphical Representations. 


\section{INTRODUÇÃO}

A educação atual conta com muitas possibilidades de transmissão de conteúdos através de aparatos tecnológicos, utilizados por professores e instrutores em aulas e cursos, sejam estes presenciais ou à distância. A educação à distância (EaD) vem desenvolvendo métodos e normativas no sentido de potencializar o emprego de mídias digitais no auxílio à educação. Neste sentido são importantes os objetos de aprendizagem (OAs) que são unidades de aprendizagem independentes que podem ser utilizados e reutilizados na elaboração de cursos e aula (WILEY, 2000). Outro aspecto que cresce e ganha importância junto à criação de conteúdo educativo é a acessibilidade. A perspectiva de incluir todas as pessoas, independentemente de suas desabilidades, é a proposta do Design Universal.

A partir dos objetos de aprendizagem e da acessibilidade a pesquisadora Claudia Mara Scudelari de Macedo desenvolveu sua tese de doutorado, defendida em 2010 na Universidade Federal de Santa Catarina (UFSC). A pesquisadora organizou um conjunto de diretrizes de acessibilidades direcionadas para a criação de objeto de aprendizagem (MACEDO, 2010). As diretrizes foram apresentadas em 43 páginas no capítulo 5 da tese.

Posteriormente, em 2014, em disciplina ministrada no Programa de pós-graduação em design da UFPR, os alunos foram incentivados a desenvolver um instrumento gráfico no sentido de facilitar o acesso e o uso das diretrizes de Macedo (2010), visando tornar as diretrizes mais acessível e eficientes para os desenvolvedores de OAs que buscam incluir a acessibilidade em seus conteúdos.

Como resultado o grupo realizou: uma representação gráfica de síntese (RGS) das citadas diretrizes, testou a RGS junto a especialista desenvolvedores de OAs, fez a análise dos resultados da testagem, e reformulou a RGS. O presente artigo tem como proposta apresentar os resultados do trabalho realizado.

\section{FUNDAMENTAÇÃO TEÓRICA}

A fundamentação aborda as diretrizes de Macedo (2010) e o conceito da representação gráfica de síntese RGS.

\subsection{Diretrizes para Desenvolvimento de Objetos de Aprendizagem Acessíveis}

As diretrizes para desenvolvimento de objetos de aprendizagem acessíveis aqui referenciadas são o resultado da pesquisa de Macedo (2010). Estas diretrizes têm fundamento nos princípios do Design Universal e nas orientações das organizações: Instrucional Management System (IMS); Global Learning Consortium (GLC); Web World Wild Web Community (W3C) e das WCAG Content Acessibility Guidelines (WCAG) segundo a figura 1. 




Figura 01 - Geração das diretrizes de acessibilidade em objetos de aprendizagem. Fonte: Macedo (2010, p.169).

A pesquisa parte dos princípios do IMS-GLC (Instrucional Management System - Global Learning Consortium), ilustrados pela figura 2.

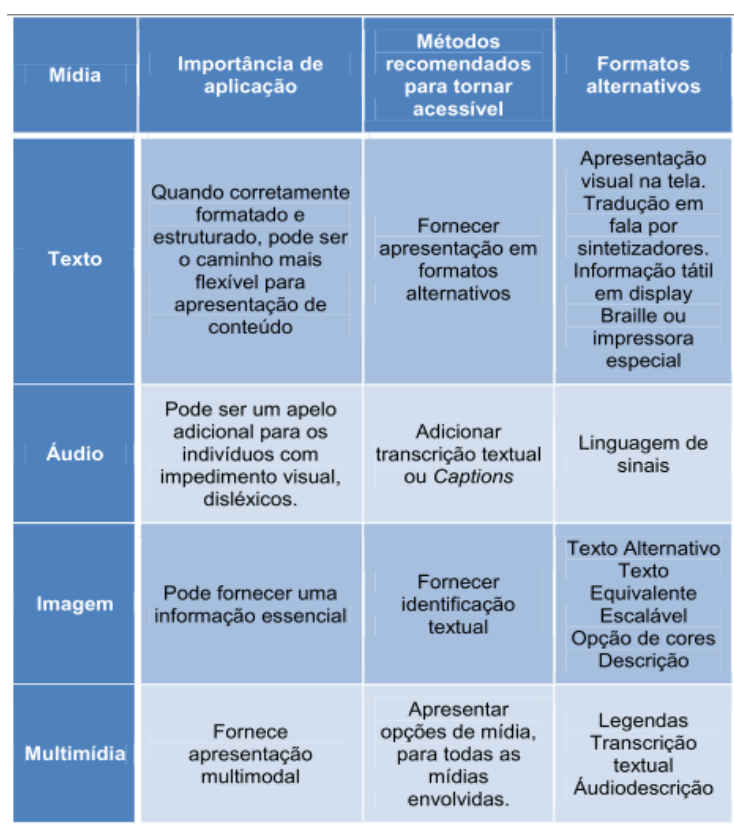

Figura 2 - Recomendações do IMS aplicada as diretrizes propostas. Fonte: Macedo (2010, p.161).

A pesquisa foi complementada pelas recomendações de acessibilidade para criação de conteúdo on-line do W3C-WCAG (World Wild Web Community - Web Content Acessibility Guidelines), ilustradas na figura 3.

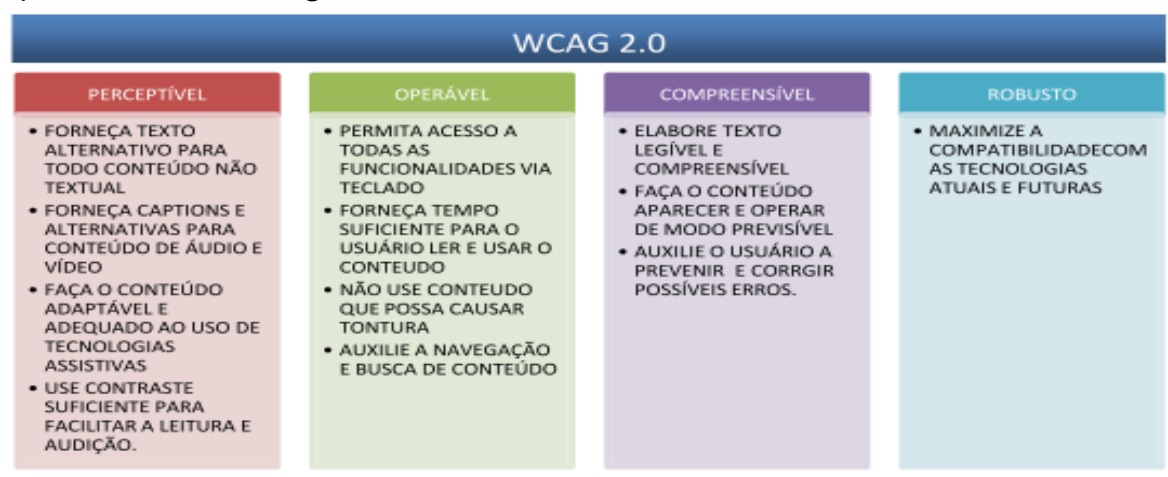

Figura 3 - Estrutura do WCAG 2.0. Fonte: Macedo (2010, p.164). 


\section{O Design Universal baseia-se em sete princípios que foram expressos em 1997 pelo The Center for Universal Design:}

Tabela 1 - Princípios de Design Universal e sua aplicações. Fonte: Molly, Mueller, Mace (1998).

\begin{tabular}{|c|c|}
\hline $\begin{array}{l}\text { PRINCÍPIO UM: } \\
\text { Uso Equitativo }\end{array}$ & $\begin{array}{l}\text { O design é útil e comercializável às pessoas com diferentes habilidades. Diretrizes: } \\
\text { 1a. Fornecer os mesmos meios de uso para todos os usuários: sempre idêntico quando possível;equivalente quando não. } \\
\text { 1b. Evite segregar ou estigmatizar quaisquer usuários. } \\
\text { 1c. Tomar providências para privacidade, segurança, e segurança igualmente disponíveis para todos os usuários. } \\
\text { 1d. Faça o design atraente para todos os usuários. }\end{array}$ \\
\hline $\begin{array}{l}\text { PRINCÍPIO DOIS: } \\
\text { Uso flexível }\end{array}$ & $\begin{array}{l}\text { O design acomoda uma ampla gama de preferências e habilidades individuais. Diretrizes: } \\
\text { 2a. Fornecer escolha dos métodos de uso. } \\
\text { 2b. Acomodar o acesso e uso de direita ou canhoto. } \\
\text { 2c. Facilitar a exatidão e precisão do usuário. } \\
\text { 2d. Fornecer adaptabilidade às ritmo do usuário. }\end{array}$ \\
\hline $\begin{array}{l}\text { PRINCÍPIO TRÊS: } \\
\text { Use simples e intuitivo }\end{array}$ & $\begin{array}{l}\text { O uso do design é fácil de entender, independentemente da experiência do usuário, conhecimento, competências } \\
\text { linguísticas, ou nível de concentração atual. Diretrizes: } \\
\text { 3a. Eliminar a complexidade desnecessária. } \\
\text { 3b. Seja consistente com as expectativas do usuário e intuição. } \\
\text { 3c. Acomodar uma ampla gama de alfabetização e competências linguísticas. } \\
\text { 3d. Organizar informações consistentes com a sua importância. } \\
\text { 3e. Fornecer eficaz sugestões e feedback durante e após a conclusão da tarefa. }\end{array}$ \\
\hline $\begin{array}{l}\text { PRINCÍPIO QUATRO: } \\
\text { Informação perceptível }\end{array}$ & $\begin{array}{l}\text { O design comunica eficazmente a informação necessária para o usuário, independentemente das condições ambientais } \\
\text { ou habilidades sensoriais do usuário. Diretrizes: } \\
\text { 4a. Use diferentes modos (pictórica, verbal, táteis) para a apresentação redundante de informações essenciais. } \\
\text { 4b. Maximizar a "legibilidade" da informação essencial. } \\
\text { 4c. Diferenciar elementos de maneiras que podem ser descritos (ou seja, torná-lo fácil de dar instruções ou orientações). } \\
\text { 4d. Proporcionar a compatibilidade com uma variedade de técnicas ou dispositivos utilizados por pessoas com limitações } \\
\text { sensoriais. }\end{array}$ \\
\hline $\begin{array}{l}\text { PRINCÍPIO CINCO: } \\
\text { Tolerância para o erro }\end{array}$ & $\begin{array}{l}\text { O design minimiza perigos e as consequências adversas de ações acidentais ou não intencionais. Diretrizes: } \\
\text { 5a. Organizar elementos para minimizar os riscos e erros: elementos mais utilizados, mais acessível; elementos perigosos } \\
\text { eliminados, isolados ou blindado. } \\
\text { 5b. Fornecer avisos de perigos e erros. } \\
\text { 5c. Fornecer falhar recursos seguros. } \\
\text { 5d. Desencorajar ação inconsciente em tarefas que exigem vigilância }\end{array}$ \\
\hline $\begin{array}{l}\text { PRINCÍPIO SEIS: } \\
\text { Baixo esforço físico }\end{array}$ & $\begin{array}{l}\text { O projeto pode ser usado de forma eficiente, confortável e com um mínimo de fadiga. Diretrizes: } \\
6 \text { a. Permitir ao usuário manter uma posição do corpo neutro. } \\
\text { 6b. Use forças de operação razoáveis. } \\
\text { 6c. Minimize ações repetitivas. } \\
\text { 6d. Minimize o esforço físico sustentado }\end{array}$ \\
\hline $\begin{array}{l}\text { PRINCÍPIO SETE: } \\
\text { Tamanho e espaço } \\
\text { para o acesso e uso }\end{array}$ & $\begin{array}{l}\text { Tamanho e espaço adequado é fornecido para abordagem, alcance, manipulação e uso, independentemente do tamanho } \\
\text { do corpo do usuário, postura ou mobilidade. Diretrizes: } \\
\text { 7a. Fornecer uma linha clara de visão para elementos importantes para qualquer usuário sentado ou em pé. } \\
\text { 7b. Dar alcance a todos os componentes para qualquer usuário sentado ou em pé. } \\
\text { 7c. Acomodar variações de mão e alça de tamanho. } \\
\text { 7d. Proporcionar um espaço adequado para o uso de dispositivos de apoio ou assistência pessoal. }\end{array}$ \\
\hline
\end{tabular}

\section{Dentre as diretrizes do Design Universal, Macedo (2010) selecionou as quatro primeiras para compor as diretrizes para os OAs acessíveis, ilustradas na figura 4.}

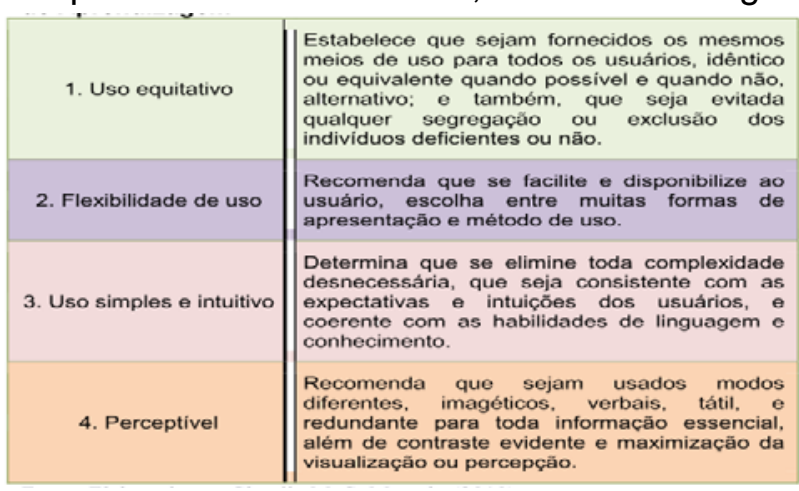


Figura 4 - Princípios de design universal aplicados em objetos de aprendizagem. Fonte: Macedo (2010, p.163)

\section{Após trabalhar na convergência das recomendações acima referenciadas foram geradas as diretrizes expostas e exemplificadas no capítulo 5 da tese de Macedo (2010) (Tabela 2).}

Tabela 2 - Diretrizes para criação de objetos de aprendizagem acessíveis. Fonte: Macedo (2010, 173 a 176).

\begin{tabular}{|c|c|c|}
\hline $\begin{array}{l}\text { DIRETRIZE } \\
\text { S }\end{array}$ & \multicolumn{2}{|c|}{$\begin{array}{l}\text { Todo conteúdo de um objeto de aprendizagem, deve apresentar ao menos: } \\
\text { - Uma mídia de acesso textual, equivalente ou alternativo. E - Uma mídia alternativa se não for possível uma mídia equivalente. }\end{array}$} \\
\hline $\begin{array}{l}\text { IMAGEM } \\
\text { EM } \\
\text { MOVIMEN } \\
\text { TO }\end{array}$ & $\begin{array}{l}\text { Vídeos, animações ou scripts devem ter: } \\
\text { - Título claro que se relacione com o tema. } \\
\text { - Descrição textual do tema do filme ou animação. } \\
\text { - Texto alternativo que descreve a função do vídeo. }\end{array}$ & $\begin{array}{l}\text { Mídia alternativa, ao menos uma opção: } \\
\text { - Transcrição completa textual ou em áudio. } \\
\text { - Áudio descrição estendida. } \\
\text { - Áudio descrição sincronizada. } \\
\text { - Legenda, Captions ou interpretação em Libras se o conteúdo for } \\
\text { sonorizado. }\end{array}$ \\
\hline $\begin{array}{l}\text { IMAGEM } \\
\text { ESTÁTICA }\end{array}$ & $\begin{array}{l}\text { Fotos, diagramas, tabelas, gráficos, desenhos, arte ANSI, } \\
\text { logos, charts, botões, imagens link, etc. devem ter: } \\
\text { - Visualização monocromática. } \\
\text { - Alto contraste. } \\
\text { - Escalonáveis, por lupa virtual até } 200 \% \text {. }\end{array}$ & $\begin{array}{l}\text { Mídia alternativa, ao menos uma opção: } \\
\text { - Texto alternativo com propósito equivalente ao da imagem. } \\
\text { - Descrição completa equivalente em Áudio ou textual. } \\
\text { - Alternativa simplificada para impressão em Braille. }\end{array}$ \\
\hline \multirow[t]{2}{*}{ TEXTOS } & $\begin{array}{l}\text { Todo texto apresentado deve ter: } \\
\text { - Fundo de cor sólida. } \\
\text { - Cores alteráveis e perceptíveis sem cor. } \\
\text { - Estrutura e formatação adequada. } \\
\text { - Equivalentes gráficos ou sonoros. }\end{array}$ & $\begin{array}{l}\text { Linguagem no texto deve ser: } \\
\text { - Clara e simples. } \\
\text { - Concisa e factual e direta. } \\
\text { - Pontuada adequadamente, para percepção dos leitores de tela. } \\
\text { - Apresentado em estilo de escrita e terminologia condizente com o } \\
\text { nível do conteúdo. } \\
\text { - Em forma de prosa. }\end{array}$ \\
\hline & $\begin{array}{l}\text { Pode ser: } \\
\text { - Transformado em página somente textual. } \\
\text { - Convertido em áudio, ou ter descrição sonora. } \\
\text { - Traduzido ou transcrito em Libras. } \\
\text { - Impresso. } \\
\text { - Visualizado na tela na forma escrita. } \\
\text { - Tátil, impresso em Braille. } \\
\text { - Imagem de texto. } \\
\text { - Texto alternativo ou descrição de outras mídias. }\end{array}$ & $\begin{array}{l}\text { Estrutura do texto deve apresentar: } \\
\text { - Identificação de cabeçalhos, e outros elementos estruturais. } \\
\text { - Organização do conteúdo de forma lógica e ordem } \\
\text { compreensível. } \\
\text { - Hierarquia de tópicos e enumeração. } \\
\text { - No máximo } 80 \text { caracteres por linha. } \\
\text { - Quebra do texto em segmentos, com título bem definido. } \\
\text { - Versão para impressão em uma única página. } \\
\text { - Abreviaturas e acrônimos especificados por extenso na sua } \\
\text { primeira ocorrência. } \\
\text { - Definição de todas as palavras ou expressões não comuns, em } \\
\text { texto alternativo ou link para glossário no documento. } \\
\text { - Não usar texto justificado nem centralmente alinhado. }\end{array}$ \\
\hline $\begin{array}{l}\text { TEXTO } \\
\text { ALTERNAT } \\
\text { IVO }\end{array}$ & $\begin{array}{l}\text { O Texto alternativo deve ser adicionado a todo conteúdo não } \\
\text { textual. } \\
\text { - É uma frase curta, suficiente para ser claro e entendido sem } \\
\text { redundância. No máximo } 150 \text { caracteres. } \\
\text { - Substitui uma imagem. } \\
\text { - É lido por leitor de tela, browser de voz, display Braille, no } \\
\text { espaço em que são colocadas as imagens. } \\
\text { - Deve fazer sentido fora do contexto (considerar os leitores de } \\
\text { tela), no contexto ou como parte do texto todo. } \\
\text { - Contribuir para o entendimento da página. } \\
\text { - Não é descrição de uma imagem, é uma Identificação sucinta } \\
\text { que esclarece a função da imagem. } \\
\text { - Quando não é suficiente, deve ser adicionada uma descrição } \\
\text { completa: Pode ser um link para outra página, ou, Pode ter até } \\
300 \text { palavras. }\end{array}$ & $\begin{array}{l}\text { Não usar texto alternativo quando se tratar de: } \\
\text { - Imagens decorativas e irrelevantes para compreensão do } \\
\text { conteúdo. } \\
\text { - Imagem que possui uma descrição no texto visível, ou uma } \\
\text { legenda clara, ou explicação no conteúdo do texto. }\end{array}$ \\
\hline TABELAS & $\begin{array}{l}\text { Devem ter: } \\
\text { - Identificação clara de títulos, cabeçalhos, linhas e colunas. } \\
\text { - Leitura linear, linha a linha. } \\
\text { - Resumo textual. } \\
\text { - Toda a função da tabela descrita em Captions. } \\
\text { - Sumário para descrever a forma da tabela. }\end{array}$ & $\begin{array}{l}\text { Tabelas complexas devem ser convertidas em tabelas simples. } \\
\text { Não devem ser usadas para formatação. }\end{array}$ \\
\hline
\end{tabular}




\begin{tabular}{|l|l|l|} 
GRÁFICOS & $\begin{array}{l}\text { Devem ser preferencialmente apresentados em forma de } \\
\text { tabelas. } \\
\text { Quando são necessários, devem apresentar: } \\
\text { - Texto descritivo do layout do gráfico, localização das variáveis } \\
\text { e resultados apresentados. } \\
\text { - Sumário do gráfico apresentado como título. }\end{array}$ & $\begin{array}{l}\text { O objetivo principal é informação e significado, e não uma } \\
\text { sequencia de dados ou números. }\end{array}$ \\
\hline ÁUDIO & $\begin{array}{l}\text { Deve apresentar opção de mídia textual: } \\
\text { - Legenda; - Captions; - Descrição completa; - Texto alternativo } \\
\text { visual; - Tradução em Língua de Sinais. }\end{array}$ & $\begin{array}{l}\text { Controles aparentes de volume, pausa, liga/desliga. } \\
\text { Não deve ter som de fundo. }\end{array}$ \\
\hline
\end{tabular}

Estas recomendações e exemplos se constituem como um material importante para desenvolvedores de OAs interessados em acessibilidade. Entretanto estão apresentadas de forma muito extensa. Foi, buscando agrupar as diretrizes e facilitar seu uso, foram desenvolvidas uma representação gráfica de síntese (RGS).

\subsection{Representação Gráfica de Síntese (RGS)}

O termo representação gráfica de síntese (RGS) foi originalmente proposto em PADOVANI, 2012. Neste artigo a autora define a RGS como 'artefatos visíveis bidimensionais estáticos criados com o objetivo de complementar a informação escrita em textos acadêmicocientíficos. Para tanto, empregam, predominantemente, os modos de representação esquemático pictórico (simplificado), sendo o texto utilizado apenas na forma de rótulos resumidos integrados a própria representação ou em legendas.' (PADOVANI, 2012, p.132).

Padovani (2013) apresenta algumas características da RGS pela perspectiva do design thinking ilustradas na figura 5. Dentre tais características, vale destacar as propriedades de síntese: uso de representações gráficas para revelar processos; a integração do texto ou narrativa na representação; o uso de representação gráfica como parte de exploração colabotariva; o uso de representação gráfica como ferramenta interativa; a exploração dos aspectos estéticos e cognitivos das representações (Figura 5).

\begin{tabular}{|c|c|}
\hline Categoria & Atividades Envolvidas \\
\hline $\begin{array}{l}\text { formação de } \\
\text { conceitos }\end{array}$ & $\begin{array}{l}\text { uso de representações gráficas para recordar conceitos } \\
\text { organização de conceitos em representações gráficas }\end{array}$ \\
\hline compreensão & $\begin{array}{l}\text { interpretação de representações visuais } \\
\text { conceitualização usando representações visuais }\end{array}$ \\
\hline aplicação & $\begin{array}{l}\text { seleção de modo apropriado de representação } \\
\text { aquisição de habilidades técnicas de representação } \\
\text { uso de princípios de percepção e design } \\
\text { aplicação do modo apropriado de representação }\end{array}$ \\
\hline sintese & $\begin{array}{l}\text { uso de representações gráficas para revelar processos } \\
\text { integração de texto ou narrativa na representação } \\
\text { uso de representação gráfica como parte de exploração colaborativa } \\
\text { uso de representação gráfica como ferramenta interativa } \\
\text { exploração dos aspectos estéticos e cognitivos das representações }\end{array}$ \\
\hline avaliação & $\begin{array}{l}\text { fazer julgamentos com base nas representações } \\
\text { avaliar o uso potencial das representações } \\
\text { avaliar a eficácia das representações }\end{array}$ \\
\hline
\end{tabular}

Figura 5: Categorias do processo de Visual Thinking adaptado de Trumbo (1999). Fonte: Padovani (2013, p.135)

Assim, a adoção da RGS para representar as diretrizes de Macedo (2010) vem no sentido de sintetizar as informações de forma que estas se tornem mais acessíveis aos usuários. 


\section{DESENVOLVIMENTO}

\subsection{Confecção da RGS}

A confecção da RGS ocorreu em duas etapas. Inicialmente foi feita a leitura do conteúdo das diretrizes e foram desenvolvidas três tentativas, denominadas RGSs primárias (figuras 6, 7 e 8). Em um segundo momento, de forma colaborativa, as RGSs foram apresentadas e debatidas pelo grupo que chegou a um consenso sobre a forma e o conteúdo desejável para a RGS final (figura 9). As Figuras 6, 7 e 8 mostram as RGS primárias:
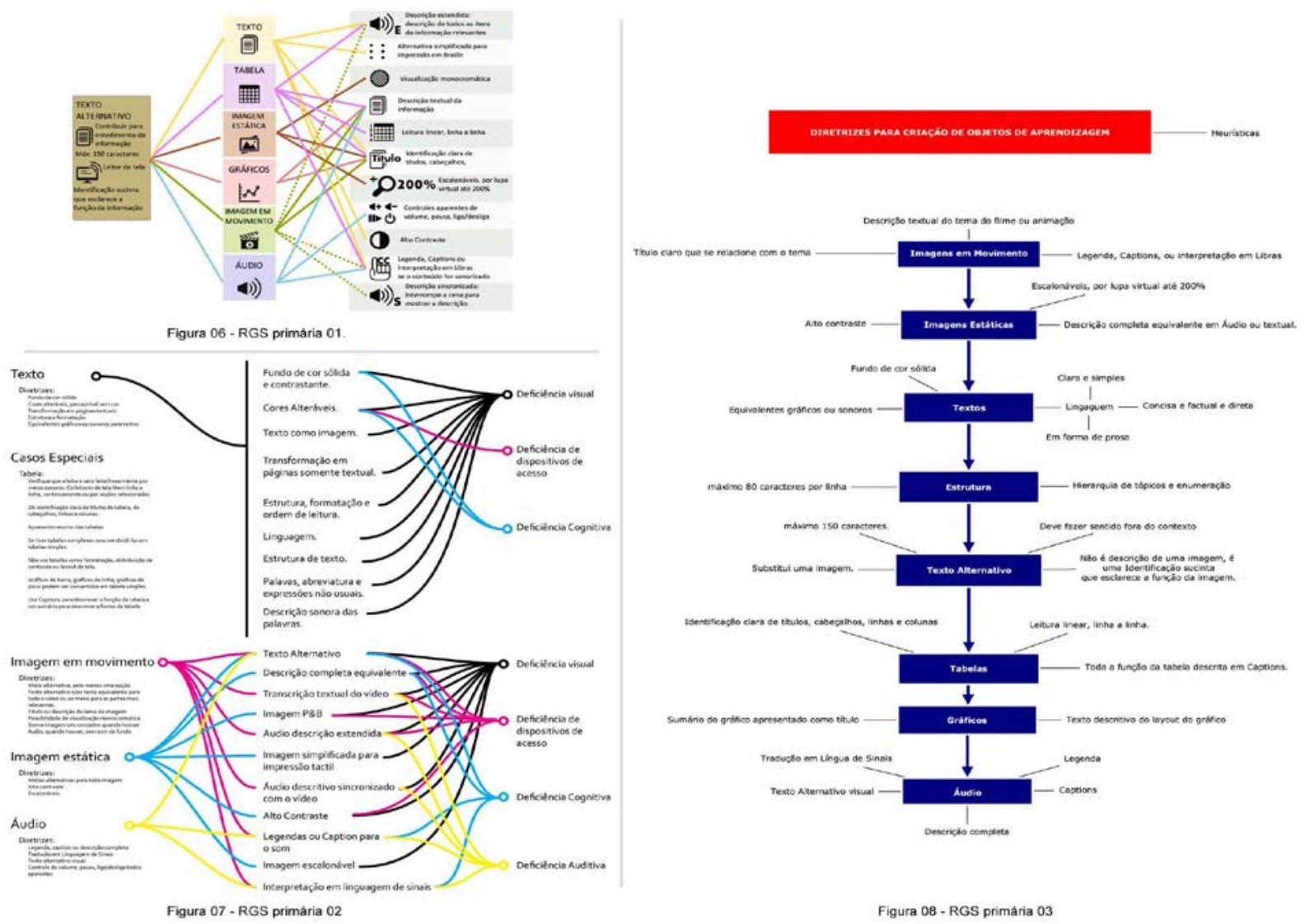

Após debatidas as RGS primárias (figuras, 6, 7 e 8) foi confeccionada a RGS final (figura 9).

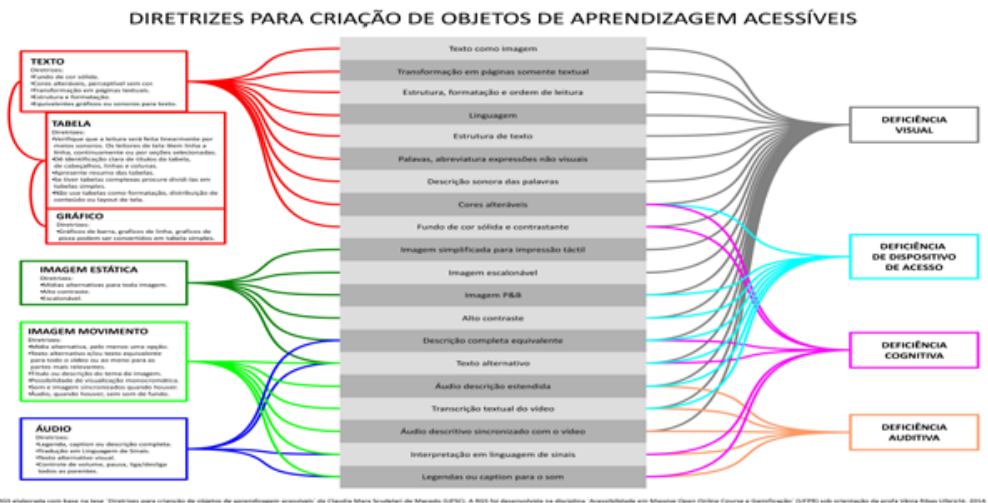


Figura 9 - RGS final das diretrizes para criação de objetos de aprendizagem acessíveis.

A RGS final (figura 9) foi composta por três colunas. Na coluna esquerda foram apresentados as mídias (texto, imagem estática, imagem em movimento e áudio), na coluna central as diretrizes propriamente ditas e na coluna direita foram relacionadas as desabilidades ou deficiências (visual, de dispositivo de acesso, cognitiva e auditiva). As conexões são feitas por linhas, uma vez que existem diretrizes que atendem diferentes desabilidades e podem ser aplicadas em mais de uma mídia. Após a confecção da RGS foram aplicados testes com os usuários finais.

\subsection{A testagem da RGS}

Com a RGS final pronta foram realizados testes junto a especialistas de OAs.

Testagem 10 primeiro avaliador aplicou teste da RGS enviado questionário via e-mail para três desenvolvedores, identificados como DS1 (pesquisador de conteúdo de aprendizagem), DS2 (web designer que trabalha em uma empresa que desenvolve conteúdo de aprendizagem para ensino a distância) e DS3 (docente e produz conteúdos de aprendizagem para o ensino médio).

Tabela 3 - Perguntas e respostas obtidas pelo avaliador 1. Fonte: Ferreira e Heemann (2014, p. 10 a 13)

\begin{tabular}{|l|l|}
\hline $\begin{array}{l}\text { Questões apresentadas pelo } \\
\text { avaliador }\end{array}$ & Respostas ou avaliações provenientes do retorno oferecido pelos avaliados \\
\hline $\begin{array}{l}\text { Você produz conteúdos de } \\
\text { aprendizagem digital? O que } \\
\text { são? }\end{array}$ & $\begin{array}{l}\text { DS1 - No momento não produzo, apenas analiso os conteúdos existentes. Tenho uma } \\
\text { proposta de pesquisa que objetiva apresentar as variáveis gráficas. } \\
\text { DS2 - Desenvolvemos conteúdo de aprendizagem para alunos do ensino fundamental, } \\
\text { principalmente como conteúdo de reforço para disciplinas regulares. } \\
\text { DS3 - Em nosso laboratório desenvolvemos como atividade de ensino, conteúdos } \\
\text { educacionais que viabilizam uma maior interação do aluno do ensino médio com os } \\
\text { conteúdos regulares, oferecendo também como objetos de aprendizagem exercícios que } \\
\text { desenvolvem a autonomia no estudo. }\end{array}$ \\
\hline $\begin{array}{l}\text { Qual o público-alvo de seu } \\
\text { trabalho com conteúdo de } \\
\text { aprendizagem? }\end{array}$ & $\begin{array}{l}\text { DS1 - Pessoas com deficiência visual. } \\
\text { DS2 - Alunos do ensino fundamental e estudantes de ensino a distância. } \\
\text { DS3 - Atualmente, dedicamos nossas atividades de projeto para produções voltadas aos } \\
\text { estudantes do ensino médio. }\end{array}$ \\
\hline $\begin{array}{l}\text { Você utiliza alguma diretriz, } \\
\text { padrão ou documento de } \\
\text { orientações para a } \\
\text { acessibilidade? Qual/quais? }\end{array}$ & $\begin{array}{l}\text { DS1 - “Sim. Diretrizes do IMS, W3C - WCAG, WAI, NCAM, NDA, UKAAF* para compilação } \\
\text { de dados visto que esses consórcios contêm diretrizes globais de acessibilidade de conteúdo } \\
\text { on-line e, por conseguinte em objetos de aprendizagem digitais, bem como as diretrizes de } \\
\text { criação de objetos de aprendizagem acessíveis, propostas por MACEDO (2010). Utilizo } \\
\text { também recomendações vindas da cartografia (LOCH, 2008) a respeito de mapas táteis. } \\
\text { *IMS -Instructional Management Systems; W3C -World Wide Web Consortium; WCAG - } \\
\text { Web Content Accessibility Guidelines; WAl e WAG1.0 Web Accessibility Guidelines 1.0; } \\
\text { NCAM - National Center for Accessible Media; NDA - National Disability Authority; UKAAF - } \\
\text { UK Association for Accessible Formats." } \\
\text { DS2 - Buscamos implementar nossos projetos pensando na experiência do usuário dentro do }\end{array}$ \\
\hline
\end{tabular}


conteúdo de aprendizagem, pensamos sempre em usabilidade e acessibilidade ao conteúdo. De diretrizes nos aproximamos da WCAG, http://www.ilearn.com.br/TR/WCAG20/ mas não atendemos a todos os quesitos. A demanda de nossos clientes não comporta o que poderíamos considerar um design universal.

DS3 - Sim, utilizamos das diretrizes e orientações delineadas pelos grupos W3C e IMS, complementamos com o trabalho apresentado por Reategui* para avaliação de objetos de aprendizagem e também as propostas de Silveira e Carneiro 2012** (Diretrizes para a avaliação da usabilidade em objetos de aprendizagem). Os projetos do laboratório buscam se adequar ao público geral embora o conteúdo seja voltado a estudantes do ensino médio.

Você conhece as diretrizes propostas por Macedo (2010)? Em positivo, utiliza estas diretrizes?

Propomos uma representação gráfica para uma visualização objetiva de diretrizes para criação de objetos de aprendizagem acessíveis. Como você avalia esta proposta? Se possível, identifique pontos negativos e positivos.
DS1 - Sim, utilizo as diretrizes relacionadas à acessibilidade de imagens estáticas.

DS2 - Não havia tido contato com a proposta da autora até este questionário.

DS3 - Fiz a leitura de um artigo da autora que demonstrava um mapeamento de conteúdo e mídias alternativas. Salvei este mapa para consultas rápidas, acredito seja da edição passada do InfoDesign. Quanto a tese indicada no link não li até o momento.

DS1 - "Achei interessante. A representação gráfica abrange uma quantidade grande de informação, porém achei meio confusa devido à grande sobreposição de linhas laterais que relacionam a deficiência às diretrizes. Não consigo imaginar uma representação estática desses conceitos. Imaginei uma representação com o esqueleto central e "boxes"' com as deficiências como se fossem "'menus"' e ao clicar no "'menu"' as diretrizes relacionadas ficariam em destaque.

Essa representação gráfica seria utilizada por quem? Pensando de acordo com as informações que adquiri com as minhas pesquisas de campo com desenvolvedores e educadores sobre imagens táteis:

Pessoas com repertório em design da informação talvez consigam compreender com mais facilidade, porém nem sempre o desenvolvedor de objeto de aprendizagem possui esse conhecimento. Para um educador, por exemplo, que muitas vezes desenvolve seus os materiais, acredito que ficaria um tanto confuso entender a representação. Acredito que se fosse algo dinâmico reduziria o esforço cognitivo.

Mas no geral a ideia é muito boa!"

DS2 - Acredito que a proposta deva ser evoluída embora pareça interessante principalmente para o desenvolvimento do conteúdo em sí do objeto de aprendizagem e suas diferentes formas de representação. Achei interessante vincular as deficiências as diretrizes o que pode facilitar o design de conteúdo para públicos específicos. Para as etapas de desenvolvimento da página acredito que seriam necessários abordar pontos técnicos como nomenclaturas, disposição do conteúdo, acesso as mídias alternativas como áudio, vídeo, texto entre outros fatores que podem melhorar a experiência de uso não tratando apenas da informação.

Um ponto negativo que deixou bastante dúvida foi o uso de texto indicando diretrizes junto aos títulos, acho que o ideal seja optar por apenas um campo contendo diretrizes, por exemplo, no campo TEXTO, diz sobre fundo de cor sólida no box, mas as linhas também trazem esta informação, inclusive em ordem diferente. Ficou confuso, afinal qual devo seguir? Outra questão foi no campo do box, cor alterável, perceptível sem cor. Não entendi o que isso quer dizer, e na tabela central o texto diz apenas cores alteráveis. Outro ponto que pode ser melhorado são as linhas, chega um momento que fica confuso, talvez alterar as cores possa ajudar ou o layout proposto mesmo.

DS3 - A proposta de representação gráfica apresentada parece se adequar aos conteudistas de objeto de aprendizagem como aponta a autora Macedo, uma vez que aborda formas de comunicação em mídias alternativas e as adequações que devem ser contempladas nas mídias em texto, aúdio, imagem e vídeo. Considero que para os designers e professores que já conhecem algumas bases de orientação como a W3C e a IMS o conteúdo proposto possa atuar como um facilitador para recordar diretrizes básicas mas não evoluí em questões mais específicas. Como pontos negativos, acredito que o conteúdo da representação não seja acessível a pessoas com desabilidades uma vez que leitores de tela não irão contemplar a leitura das linhas que ligam os grupos às diretrizes, é importante compreender que parte dos desenvolvedores pode possuir desabilidades. Vincular as deficiências ou desabilidades à diretrizes pode ser interessante, mas a acessibilidade não deve ser pensada com base nas desabilidades mas sim no acesso comum a todos. O conteúdo descrito apesar de básico atende a diversas desabilidades. Quanto ao design da proposta, este deve ser revisado, as cores parecem ser de difícil diferenciação principalmente por pessoas com daltonismo. Quanto ao conteúdo textual, é necessário cuidado com a informação uma vez que existem 


\begin{tabular}{|l|l|} 
& $\begin{array}{l}\text { textos repetidos nas caixas de texto e no quadro central. } \\
\text { Acredito que a intenção de simplificar as diretrizes de acessibilidade seja digna, mas é } \\
\text { necessário considerar o grupo de características não contempladas, como questões sociais, } \\
\text { culturais e do plano de educação do governo federal, além de questões técnicas para o } \\
\text { aprofundamento das diretrizes. }\end{array}$ \\
\hline $\begin{array}{l}\text { Qual seu papel frente ao } \\
\text { público alvo? Docente, } \\
\text { desenvolvedor, web designer } \\
\text { etc. }\end{array}$ & $\begin{array}{l}\text { DS1 - Pesquisador, desenvolvedor. } \\
\text { DS2 - Web designer. } \\
\text { DS3 }- \text { Sou professor no curso de graduação em Design da [omitido pelos autores], no } \\
\text { laboratório gráfico desenvolvo com os alunos da graduação atividades de projeto sobre } \\
\text { conteúdos para objetos de aprendizagem, como foco são objetivados os conteúdos } \\
\text { relevantes para estudantes do ensino médio. }\end{array}$ \\
\hline
\end{tabular}

$\mathrm{Na}$ avaliação de resultados, o primeiro avaliador conclui que na opinião dos respondentes a RGS possibilitou uma visão externa do conteúdo, mas que ainda é de difícil compreensão para os desenvolvedores que não tiveram contato anterior com a tese de Macedo (2010). Também apontam os problemas formais da RGS. Os avaliadores argumentam que ficou evidente que a RGS deve ser repensada especialmente no tratamento formal dado as linhas e as cores. (FERREIRA e HEEMANN, 2014)

\section{Testagem 2 O segundo avaliador aplicou teste de validação da RGS através de questionário respondido por cinco pessoas, e chegou a seguinte conclusões.}

Tabela 4 - Resultados obtidos pelo avaliador 2. Fonte: Romanus, Heemann e Ulbritch (2014, p.10).

\begin{tabular}{|c|c|}
\hline Questões apresentadas pelo avaliador & Respostas ou avaliações provenientes do retorno oferecido pelos avaliados \\
\hline $\begin{array}{l}\text { Informações de contato e de trabalho: } \\
\text { - Nome, especialidade, e-mail. } \\
\text { - ( ) freelancer, ( ) empregado em empresa, } \\
\text { ( ) dono de empresa ( ), outro. } \\
\text { - Nome da empresa ou instituição. } \\
\text { - Descreva brevemente sua especialidade } \\
\text { com OAs e/ou com acessibilidade. }\end{array}$ & $\begin{array}{l}\text { A primeira profissional consultada possui experiência tanto em design para web } \\
\text { quanto em programação. Teve também participação em um projeto de } \\
\text { desenvolvimento de mídia inclusiva de Apoio a Educação Ambiental com foco na } \\
\text { Bacia Hidrográfica do Rio Belém5. } \\
\text { Os outros quatro especialistas consultados são profissionais da equipe de } \\
\text { desenvolvimento da PUC-PR, sendo que } 2 \text { são designer gráficos e ilustradores, } 1 \text { é } \\
\text { web designer e } 1 \text { é programador. }\end{array}$ \\
\hline $\begin{array}{l}\text { Avaliação da RGS: } \\
\text { - Analisando a RGS relacionada, ela auxilia } \\
\text { o desenvolvimento de objetos de } \\
\text { aprendizagem web acessíveis? ( ) sim ( ) } \\
\text { não - Comente, por favor: } \\
\text { - Segundo seus conhecimentos de } \\
\text { acessibilidade na web, a RGS está } \\
\text { condizente às diretrizes atuais? ( ) sim ( ) } \\
\text { não - Comente, por favor: } \\
\text { - Você acha que é necessária alguma } \\
\text { mudança, ou aprimoramento na RGS } \\
\text { apresentada? ( ) sim ( ) não - Comente, por } \\
\text { favor. }\end{array}$ & $\begin{array}{l}\text { A primeira profissional considerou a RGS gerada de fato uma ferramenta que auxilia } \\
\text { o desenvolvimento de OAs acessíveis na web, pois resume de forma sintética os } \\
\text { elementos essenciais para tal desenvolvimento. No entanto, a avaliadora também } \\
\text { observou a ausência de alguns um fatores que considerou importante: não há uma } \\
\text { especificação sobre como proceder, no caso em que o usuário deve lidar com um } \\
\text { formulário. } \\
\text { Como pontos fortes, a avaliadora destacou que a RGS gerada auxilia a tornar a } \\
\text { interface perceptível e compreensível, mas que esta também precisa ser operável e } \\
\text { robusta (4 princípios WCAG - Web Content Accessibility Guidelines6). Seriam } \\
\text { relevantes também as categorias na coluna esquerda para formulários } \\
\text { (especialmente, botões), tipos de alertas/feedback da interface e teclas de atalho. } \\
\text { Na exibição do bloco central da RGS, seria necessário eleger e mostrar quais ações } \\
\text { são tidas como indispensáveis para se produzir e alcançar um objeto minimamente } \\
\text { acessível. Essa recomendação leva em conta que a execução de todas as ações } \\
\text { sugeridas pode ser muito difíceis ou mesmo inviáveis. Com o atendimento de } \\
\text { determinados aspectos, já seria possível considerar um objeto satisfatoriamente } \\
\text { acessível. Finalmente, coube a recomendação de que poderia ficar mais clara a } \\
\text { relevância da estrutura (hierarquia) para montagem do objeto, visto que esta } \\
\text { estrutura influencia e potencializa (positiva ou negativamente) o uso da interface e }\end{array}$ \\
\hline
\end{tabular}


suas interações.

Entre outros quatro especialistas, nenhum dos consultados tem experiência específica com acessibilidade. Talvez por esse motivo, nenhum dos especialistas sugeriu mudanças na representação e foram unanimes em considerem a RGS útil e condizente com os conhecimentos de cada um. Cabe ressaltar, contudo, que 3 dos consultados mencionaram que desejariam desenvolver objetos mais acessíveis, aumentar seus conhecimentos sobre o assunto e dominar softwares de desenvolvimento para esse fim.

O segundo avaliador aponta que a RGS concebida de modo colaborativo se mostrou eficaz no auxílio aos profissionais. Ressaltando que a RGS não pode ser considerada o único instrumento a ser utilizado quando se almeja a acessibilidade na web. (ROMANUS, HEEMANN e ULBRICHT, 2014)

Testagem 30 terceiro avaliador organizou um grupo focal realizado em uma empresa desenvolvedora de MLGs (Mobile Learning Games) com quatro participantes e um mediador, com duração de 130 minutos. O objetivo foi avaliar a RGS das diretrizes para criação de MLGs como OAs acessíveis. O grupo focal foi planejado em três momentos distintos: - Avaliação da compreensão da RGS; - Avaliação de aplicação da RGS em situação real; - Realização do agrupamento dos comentários mais relevantes. Obteve como resultado a seguinte considerações:

Tabela 5 - Resultados obtidos pelo avaliador 3. Fonte: Dubiela (2014, p. 9 a 11).

\begin{tabular}{|c|c|}
\hline Questões apresentadas pelo avaliador & espostas ou avaliações provenientes do retorno oferecido pelos avaliados \\
\hline $\begin{array}{l}\text { 1) Avaliação da compreensão da RGS tendo como } \\
\text { variáveis: } \\
\text { 1.1) Existe uma leitura clara do que se trata a imagem } \\
\text { (a RGS)? } \\
\text { 1.2) É possível destacar uma hierarquia nas } \\
\text { informações? } \\
\text { 1.3) É possível agrupar as informações de acordo com } \\
\text { semelhanças? } \\
\text { 1.4) É possível estabelecer correlações simples e } \\
\text { complexas entre as unidades? }\end{array}$ & $\begin{array}{l}\text { Na caixa de TEXTO da imagem representativa das Diretrizes para Criação de Objetos de } \\
\text { Aprendizagem Acessíveis foi recomendado a retirada dos itens "transformar em páginas } \\
\text { textuais" e "estrutura e formatação" uma vez que o respeito a esses itens em um MLG } \\
\text { inviabilizaria o projeto. } \\
\text { Na caixa da TABELA e GRÁFICO, foi recomendado ressaltar o uso dos itens "se tiver } \\
\text { tabelas complexas procure dividí-las em tabelas mais simples" e "gráficos de barra, } \\
\text { gráficos de linha, gráficos pizza podem ser convertidos em tabelas simples", uma vez que } \\
\text { em ambos os casos acabam sendo técnicas muito úteis de desenvolvimento e que trazem } \\
\text { resultados na compreensão de um MLG. Os participantes do grupo focal rejeitaram o item } \\
\text { "não use tabelas como formatação, distribuição de conteúdo ou layout de tela", uma vez }\end{array}$ \\
\hline $\begin{array}{l}\text { 2) Avaliação de aplicação da RGS em situação real } \\
\text { tendo como variáveis: } \\
\text { 2.1) É possível identificar nas variáveis da caixa do } \\
\text { TEXTO informações de grande relevância para um } \\
\text { trabalho voltado a acessibilidade? } \\
\text { 2.2) É possível identificar nas variáveis da caixa } \\
\text { TABELA informações de grande relevância para um } \\
\text { trabalho voltado a acessibilidade? } \\
\text { 2.3) É possível identificar nas variáveis da caixa }\end{array}$ & $\begin{array}{l}\text { Na caixa IMAGEM ESTÁTICA, foi ressaltado o uso do item "alto contraste" e destacado } \\
\text { que o item "mídias alternativas para toda imagem" seria inábeis em uma estrutura de } \\
\text { MLGs, a não ser que possa ser considerado como mídias alternativas outros modelos de } \\
\text { dispositivos móveis. }\end{array}$ \\
\hline $\begin{array}{l}\text { GRÁFICO informações de grande relevância para um } \\
\text { trabalho voltado a acessibilidade? } \\
\text { 2.4) É possível identificar nas variáveis da caixa } \\
\text { IMAGEM ESTÁTICA informações de grande relevância } \\
\text { para um trabalho voltado a acessibilidade? } \\
\text { 2.5) É possível identificar nas variáveis da caixa } \\
\text { IMAGEM EM MOVIMENTO informações de grande } \\
\text { relevância para um trabalho voltado a acessibilidade? } \\
\text { 2.6) É possível identificar nas variáveis da caixa ÁUDIO } \\
\text { informações de grande relevância para um trabalho } \\
\text { voltado a acessibilidade? }\end{array}$ & $\begin{array}{l}\text { Na caixa IMAGEM MOVIMENTO, os avaliadores do grupo focal fizeram uma ressalva de } \\
\text { uso para o item "mídia alternativa, pelo menos uma opção", por não observarem diferença } \\
\text { com o item descrito no parágrafo anterior. Por outro lado, destacaram com grande } \\
\text { entusiasmo os itens "possibilidade de visualização monocromática" e "áudio, quando } \\
\text { houver, sem som de fundo". Nesses casos foram descritos como itens muito úteis no } \\
\text { desenvolvimento de MLGs. } \\
\text { Na caixa de ÁUDIO, os avaliadores destacaram que os itens "legenda, caption ou } \\
\text { descrição completa" e "controle de volume, pausa, liga/desliga" são muito bons para } \\
\text { serem pensados em projetos, e que normalmente já o são em algum nível de } \\
\text { planejamento, mas que, o item "tradução em linguagem de sinais" tornaria o projeto de }\end{array}$ \\
\hline
\end{tabular}


$\mathrm{Na}$ conclusão o terceiro avaliador aponta que os avaliados ficaram muito satisfeitos em participar do grupo focal, a expectativa de poderem cruzar a teoria com a prática foi muito bem-vista e solicitaram uma cópia da RGS para futuras aplicações. (DUBIELA, 2014)

Após a realização dos testes os dados foram confrontados para a análise dos resultados.

\subsection{A análise dos resultados}

Observa-se que as testagens tiveram enfoques diferentes que resultaram em contribuições para uma reformulação da RGS. Entre os especialistas alguns têm experiência em acessibilidade e outros não, mas todos emitiram opiniões sobre a RGS. É possível analisar estas respostas pela perspectiva do Design da Informação e observar os resultados em três níveis: aspectos sintáticos com sugestões sobre questões formais; aspectos semânticos com sugestões de conteúdo e pragmáticos com sugestões sobre a forma de uso.

Tabela 6 - Análise dos resultados obtidos nos testes.

\begin{tabular}{|c|c|}
\hline $\begin{array}{l}\text { Aspectos sintáticos } \\
\text { (questões relacionadas a } \\
\text { aspectos formais da RGS) }\end{array}$ & $\begin{array}{l}\text { Na testagem } 1 \text { foram apontadas dificuldade de visualização pela sobreposição de linhas e } \\
\text { questionamento do uso de cores (especialmente para casos de daltonismo). Também foi apontado } \\
\text { que os textos indicando diretrizes ficam próximos ao título gerando dúvida. } \\
\text { As testagens } 2 \text { e } 3 \text { não trouxeram apontamentos de ordem formal. }\end{array}$ \\
\hline $\begin{array}{l}\text { Aspectos semânticos } \\
\text { (questões relacionadas ao } \\
\text { conteúdo da RGS) }\end{array}$ & $\begin{array}{l}\text { Na testagem } 1 \text { indica uma repetição de informação na primeira coluna e na coluna central da } \\
\text { RGS. Faz consideração sobre a forma de vincular as deficiências às diretrizes argumentando que } \\
\text { a acessibilidade não deve ser pensada com base nas desabilidades e sim no acesso a todos. } \\
\text { Na testagem } 2 \text { ocorre a sugestão de incluir categorias na coluna esquerda para formulários, tipos } \\
\text { de alertas/feedback da interface e teclas de atalho. Na exibição do bloco central apresentar quais } \\
\text { seriam as ações indispensáveis para alcançar objeto minimamente acessível. } \\
\text { Na testagem } 3 \text { foram apontados questionamentos sobre diversos itens como: "transformar em } \\
\text { páginas textuais", "estrutura e formatação" e outros fazendo avaliação destes conteúdo aplicados } \\
\text { a MLGs. }\end{array}$ \\
\hline $\begin{array}{l}\text { Aspectos pragmáticos } \\
\text { (questões relacionadas a } \\
\text { utilização da RGS) }\end{array}$ & $\begin{array}{l}\text { Na testagem } 1 \text { ocorreu a sugestão de se desenvolver uma RGS Dinâmica. Foram feitas } \\
\text { considerações em relação a dificuldade de compreender a RGS por usuários sem conhecimento } \\
\text { prévio das diretrizes, ou, uma possível dificuldade para compreensão da RGS por pessoas não } \\
\text { familiarizadas com design da informação. Alerta também sobre questões sociais, culturas dos } \\
\text { usuários e do plano de educação do governo. } \\
\text { Na testagem } 2 \text { existe foi levantado o problema da falta de instruções de uso. } \\
\text { Na testagem } 3 \text { não foram evidenciadas as questões pragmáticas. }\end{array}$ \\
\hline
\end{tabular}

\subsection{Reformulação da RGS}

Ao analisar os resultados das testagens e identificados os pontos negativos; a RGS foi reformulada tendo as seguintes alterações:

Em resposta as questões formais - aspectos sintáticos - onde observou-se dificuldade em 
relação as linhas e cores da RGS, foram alteradas algumas linhas para tracejados e pontilhados, mas não foi feita alteração cromática.

Em resposta as questões de conteúdo - aspectos semânticos - não foram feitas alterações pois estas dizem respeito ao material desenvolvido por Macedo (2010) e fogem da competência do grupo desenvolvedor da RGS. Assim, no sentido de manter a fidelidade com o material elaborado por Macedo (2010) as sugestões de conteúdo não foram contempladas na presente reformulação.

Em resposta a questões de uso - aspectos pragmáticos - a constatação de que a RGS não é um instrumento autônomo e que necessidade de instruções e instrumentos complementares, existe a proposta de desenvolver um MOOC com o conteúdo do capítulo 5 da tese de Macedo (2010), onde as diretrizes para criação de objetos de aprendizagem acessíveis serão apresentadas com mais detalhes aos interessados em utilizá-las.

A Figura 10, apresenta a RGS reformulada.

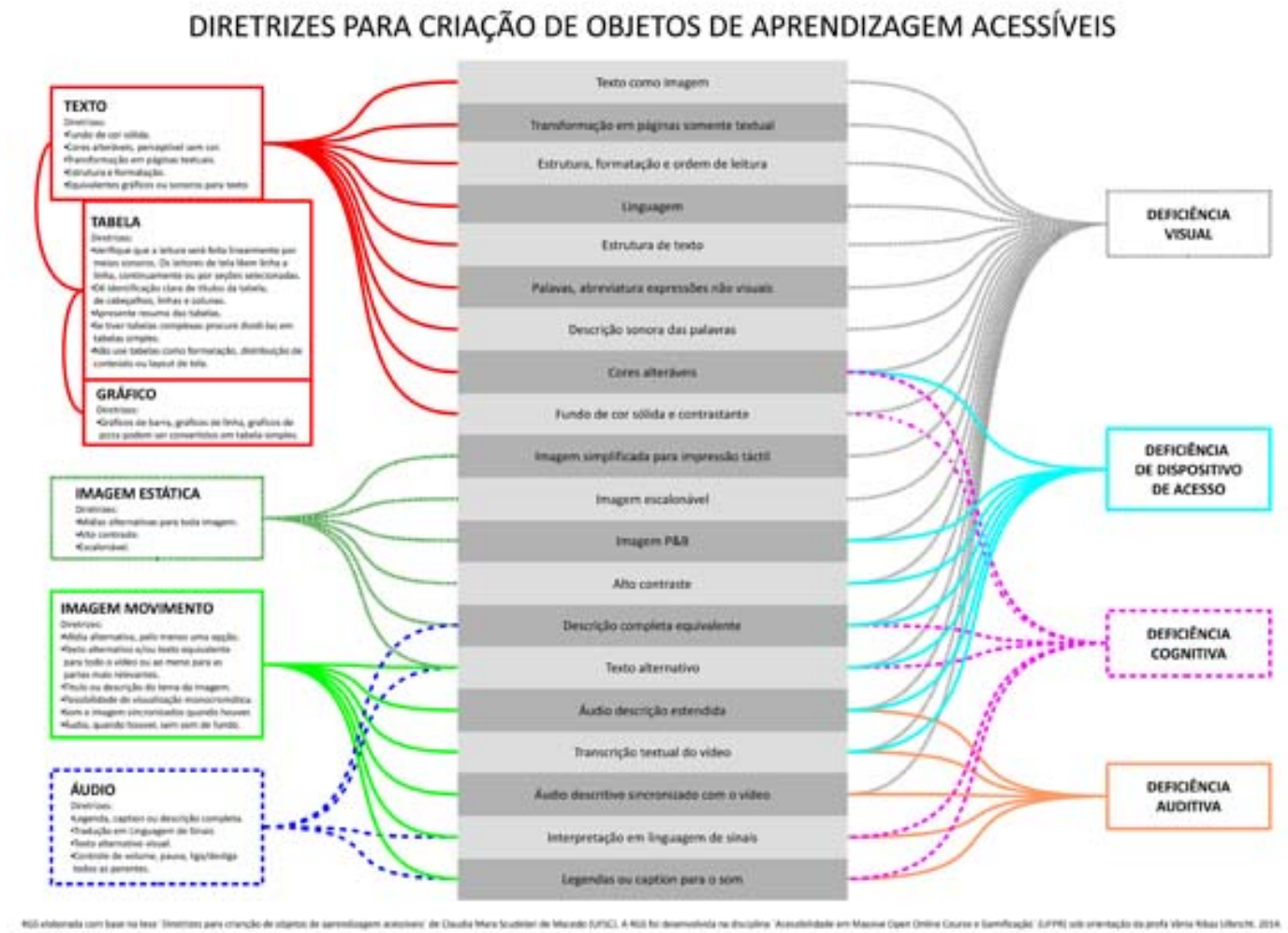

Figura 10 - RGS Reformulada.

\section{CONSIDERAÇÕES FINAIS}

A representação gráfica de síntese (RGS) desenvolvida de modo colaborativo, demonstrou ser uma ferramenta útil para sintetizar, promover acesso e facilitar o uso das diretrizes de Macedo (2010). Após a realização das testagens e observar as deficiências da RGS ocorreu uma reformulação dos quesitos formais, entretanto as considerações sobre conteúdo e 
forma de utilização da RGS podem ainda ser tratadas no sentido de se obter um instrumento com maior facilidade de uso. Por questão de tempo não foi possível fazer o teste da nova RGS, o que deve ser realizado em futuro próximo.

\section{REFERÊNCIAS BIBLIOGRÁFICAS}

DUBIELA, R. P. Proposta de utilização das diretrizes para utilização de objetos de aprendizagem em projetos de mobile learning games. 2014. Artigo submetido ao CONAHPA. Congresso Nacional de Ambientes hipermídia para aprendizagem. A ser realizada em São Luis MA de 17 a 20 de junho de 2015.

FERREIRA, G.P.G. e HEEMANN, A. Compreensão de diretrizes da acessibilidade para criação de objetos de aprendizagem através de uma representação gráfica de síntese. 2014. Artigo submetido ao CONAHPA. Congresso Nacional de Ambientes hipermídia para aprendizagem. A ser realizada em São Luis MA de 17 a 20 de junho de 2015.

MACEDO, C.M.S. Diretrizes para desenvolvimento de objetos de aprendizagem acessíveis. Tese de doutorado. Universidade Federal de Santa Catarina (UFSC) 2010.

PADOVANI, S. Representações gráficas de sínteses: artefatos cognitivos. Rio de Janeiro: Educação Gráfica, Ano 2012. V.16, n.02. p.123-142. ISSN 2179-7374.

ROMANUS, J.S., HEEMANN, A. e ULBRICHT, V.R. Representação gráfica de síntese (RGS) de diretrizes de acessibilidade para objetos de aprendizagem na web. 2014. Artigo submetido ao CONAHPA. Congresso Nacional de Ambientes hipermídia para aprendizagem. A ser realizada em São Luis MA de 17 a 20 de junho de 2015.

STORY, M., MUELLER, J., MACE, R. (1998) THE UNIVERSAL DESIGN FILE Designing for People of All Ages and Abilities. NC State University: Published by The Center for Universal Design [http://www.ncsu.edu/ncsu/design/cud/pubs p/pudfiletoc.htm] 1998.

TRUMBO, J. Visual literacy and science communication, Science communication, 20, 1999. p.409425.

WILEY, D. Learning objects and instrucional design theory. 2000. 